\title{
Scenario-planning in strategic decision-making: requirements, benefits and inhibitors
}

\author{
Danielle Meyerowitz \\ Gordon Institute of Business Science, University of Pretoria \\ Charlene Lew \\ Gordon Institute of Business Science, University of Pretoria * \\ Göran Svensson \\ Kristiania University College
}

\author{
*Corresponding author \\ Charlene Lew (lewc@gibs.co.za) \\ Gordon Institute of Business Science, University of Pretoria, PO Box 787602, Sandton 2146, South Africa
}

Danielle Meyerowitz is a learning design expert and MBA graduate of the University of Pretoria's Gordon Institute of Business Science

Charlene Lew is a senior lecturer in the field of Organizational Behavior and works in the area of behavioral decision-making

Göran Svensson is a Professor at the Institute of Marketing, Kristiania University College as well as Professor at Halmstad University in Sweden and is editor of the European Business Review, and member of numerous other editorial boards.

\begin{abstract}
Purpose - To explore the corporate requirements, benefits and inhibitors of scenario-planning in strategic decision-making.
\end{abstract}

Design/Methodology/Approach - Based on a sample of fifteen case studies with executives in the South African context to reveal the perceived corporate requirements, benefits and inhibitors of scenario-planning.

Findings - From the cases it is evident that industry, organizational and leadership related factors enable or inhibit scenario-planning. Requirements, benefits and inhibitors are revealed in strategic decision-making.

Research limitation/implications - Further research to determine supportive tools and technologies for enabling scenario-planning across multiple contexts is needed.

Practical implications - Expands insights into the requirements, benefits and inhibitors of scenario-planning in strategic decision-making.

Originality/value - Given the increasing complexity of the business environment, a framework of scenario-thinking is presented and recommend greater emphasis on developing strategic decision-making competence, changed mindsets, and organizational agility. 
Keywords - Scenario-planning, Scenario-thinking, Strategic choice, Requirement, Benefit, Inhibitor

Paper type - Research article

\section{INTRODUCTION}

As the rate of change increases, business leaders make decisions in complex and uncertain business systems (Sargut and McGrath, 2011). Within these systems, organizational survival depends on executives' strategic agility, where contrasting capabilities, flexibility and 'mindful responses' enable the longevity of firms (Lewis, Andriopoulos and Smith, 2014). One of the key requirements to obtain such agility is strategic foresight (Hammoud and Nash, 2014). Strategic foresight entails a set of methods, processes and tools available to leaders in their decision-making (Vecchiato and Roveda, 2010; Vecchiato, 2012).

Corporate foresight is a source of future competitive advantage. According to Rohrbeck, Battistella and Huizingh $(2015$, p. 2) it "creates value through providing access to critical resources ahead of competition, preparing the organization for change, and permitting the organization to steer proactively towards a desired future."

Scenario planning is one such tool that assists leaders in making sense of the unknown future. World War II already offers excellent examples of how military planners developed a series of alternatives in response to potential enemy actions. Business leaders, faced by increasingly complex contexts, and armed with knowledge of game theory and increasing computer processing power, quickly adopted the use of strategic foresight through scenarios (Burt, Wright, Bradfield, Cairns and van der Heijden, 2005). There is a fundamental assumption that scenario-planning is a universally useful tool to enable executives to make better decisions. Arguably, having greater insight into potential futures gives greater flexibility and more intuitive responses to whatever future occurs. In order to be useful, scenario-planning needs to be effective. Ramírez and co-authors (2017) list as requirements for effective scenarios a) multi-party perspectives; b) a willingness to invest time and resources and c) understanding plausible rather than possible futures, thus incorporating the element of likelihood. In this study we seek to understand what further requirements there may be for successful scenarios, what executives may seek to gain from such activities, and what may prevent them from using them in an emerging market context. In other words, the research objective is to explore the corporate requirements, benefits and inhibitors of scenario-planning in strategic decisionmaking.

This article offers theoretical considerations of the requirements of scenario-planning, benefits, challenges and systemic requirements thereof. It then shows the research methodology and key findings from this qualitative study of the actual utilization of scenario-planning. This leads to research and managerial implications as well as conclusions to overcome the inhibitors and optimize the benefits thereof. 


\section{THEORETICAL CONSIDERATIONS}

\subsection{Corporate foresight}

Since organizations seek to remain agile in an uncertain environment, corporate foresight tools, such as scenario-planning, may prove useful in strategic decision-making. Corporate foresight requires organizations to incorporate three practices in decision-making by perceiving the drivers of change to lessen uncertainty, prospecting what the effects of these signals of change will be on the organization and probing what action the organization should take (Hojland and Rohrbeck, 2018). Corporate foresight has many benefits, such as enabling innovativeness through organizational learning (Yoon, Kim, Vonortas and Han, 2018), greater vigilance as seen in the intensity of research and development activities (Kum, 2017), as well as organizational profitability and growth in market valuation (Rohrbeck, Kum and Jissink, 2017 in Hojland and Rohrbeck, 2018) to mention a few.

Given the growing interest in the value and requirements of corporate foresight, exploring the specific value, needs and also inhibitors of scenario-planning is significant.

\subsection{Requirements of scenario-planning}

Literature suggests that the success of scenario-planning is contingent upon proper information usage, an effective process, as well as the nature of the scenarios themselves.

Firstly, effective information usage and processing in scenarios require proper understanding of socio-political and economic systemic forces, industry trends, and competitor behavior (Wilson and Ralston, 2006). Furthermore, scenarios could be affected by both decision-making and leadership styles as well as internal and external environmental information (Chermack et al., 2010). Harris (2014) cautions against common mistakes in scenario processes such as focusing on the wrong variables, ignoring real threats or inadequate research. The collective wisdom of the organization, insight into the company's risk/return preferences, and clear focus on core issues only may also be required (Werner, 1990).

Secondly, the process needs to be appropriate. In multi-step scenario processes each step has specific skills requirements attached to it (Chermack, 2011). Ineffectiveness in any of the steps, be it the inputs provided, exercises used to develop scenarios or implementation of actions will result in poorer scenario-planning. The time and energy requirements of generating scenarios, as well as stakeholder behavior and scenario-planning team interactions may also impact effectiveness (Chermack and Nimon, 2013; Cairns, Goodwin and Wright, 2016).

Thirdly, the output of the planning needs to be "believable, internally consistent, and compelling" and sufficiently differentiated to be of value in strategy (Wilburn and Wilburn, 2011, p. 172).

Overall the literature suggests that strategic decision-makers operating in complex contexts may benefit from scenario-planning when information and process elements result in effective scenarios. The question still needs to be answered whether these benefits are realized in practice and whether scenarios are suitably developed. 


\subsection{Benefits of scenario-planning}

The theorized benefits of scenario-planning are contained in definitions thereof, such as Chermack and Lynham (2002, p. 376) who define it as: "a process of positing several informed, plausible and imagined alternative future environments in which decisions may be played out for the purpose of changing current thinking, improving decision-making, enhancing human and organization learning and improving performance."

Considering the Shell case, scenarios enable decision-makers to pre-evaluate their options (Duncan and Wack, 1994) and enable institutional learning and adjustment of business models (de Geus, 1988). Chermack and Swanson (2008) argue that scenario-planning, which helps people to see things differently, is a key strategic learning tool and a better way of strategizing as it involves a wide range of organizational members and explores the "emergent nature of the contextual environment" (p. 133). They hold that scenarios offer a pre-experience of the future and a means to anticipate and avoid crises.

At the same time, a useful framework developed by Van der Merwe (2008) indicates eight strategic ways in which scenario-planning may be used and associated with benefits, such as: the ability to test for robustness of decisions; developing a common perspective; engaging people; aligning policies; focusing strategic conversations; sustaining organizational development; probing assumptions about the environment; as well as advancing personal strategies in coaching. Most pertinently the framework highlights the ability to develop scenario thinking which is "embedded in all decision-making" (p. 225). Anecdotal case evidence of companies shows both that worst case scenarios can encourage proactive responses to environmental changes and chaos, and that scenarios are more effective than predictions in anticipating future events (Wilburn and Wilburn, 2011).

McWhorter and Lynham's (2014) review of literature indicates further benefits of scenarios, namely: changed institutional and collective learning, increased strategy development and execution capability with clarity of strategic options, organizational performance and several organizational behavior-based improvements such as cross-functional communication, disagreement management and coaching of leaders. Chermack et al. (2015) found that scenario-planning improves the perception of the creative organizational climate. Specifically, participants perceived it to develop freedom and a sense of independence, trust and emotionally safe relationships, time to explore new ideas, and a spontaneous playful atmosphere.

Overall this high-level review shows that there are many premised benefits of scenarioplanning, some dealing with enabling strategic capability, and others relating to organizational behavior. Research findings to support theorized benefits are sparse however. Chermack and Nimon (2013) admit that the majority of relationships between scenario-planning and theoretical outcomes still remain to be investigated.

\subsection{Inhibitors in scenario-planning}

Along with the various requirements and benefits of effective scenarios mentioned above, this study emphasizes the inhibitors in scenarios. In order to make sense out of complex environments humans need to build connections or "scaffolds" between tacit or new knowledge and codified knowledge, to which meaning has already been assigned (Brockmann and Anthony, 2002). 
The scenario-planning tool introduces leaders to tacit knowledge outside their frame of reference and enables them to assign meaning to it. This process develops decision-makers' anticipation abilities and "foresight attitude" (Bootz, 2010, p. 1589). In simple terms this means that decision-makers question their own assumptions, frames of reference and knowledge sources. As knowing is a prerequisite of scenarios it is important to note that not everything is knowable, but there are inhibitors.

Snowden's (2003) Cynefin model differentiates amongst inhibitors of what's known, where cause and effect is understood and predictable, what's knowable, where sufficient data would move it into the realm of the known, what's complex, where in social systems the cause and effect can only be deciphered after the event, and what's chaotic, where cause and effect are not recognizable. This seems to suggest that the value of scenarios may only be discerned after events have taken place, as most scenarios are developed for social systems.

One may argue that the ability to anticipate and think about multiple futures enables strategic agility or the ability to have "flexible, mindful responses to constantly changing environments" (Lewis et al., 2014, p. 58). Furthermore, the development of scenarios often helps explore paradoxical views and forecasts of the future, and brings to the fore contrasting priorities for executives (Ringland, 2010). Thus, scenarios at individual level bring about new insights and anticipatory thinking to overcome inhibitors, and at collective level challenge set knowledge frames.

In scenario analysis there are several inhibitors to overcome. Chermack et al. (2010) believe that the process requires deeper thinking regarding environmental forces in events. Wilson and Ralston (2006) name intuition, creativity to generate alternatives, and curiosity about the environment and opportunities as scenario requirements. To explicate, intuitive thinking is fast and emotionally charged judgements outside conscious awareness and reasoning (Smith, 2008). This is essential as no amount of analysis will offer a decision-maker a clear answer to handle inhibitors in the complex system of business.

Nevertheless, larger organizations tend to discourage intuitive decision-making in favor of rules, procedures and more deliberate processes (Matzler et al., 2014). Interestingly, Chermack and Nimon (2013) found that decision-makers shift from rational decision-making styles to intuitive styles after scenario-planning. Creative thinking to handle inhibitors may occur through the scenario process when the imagination is stretched (Ringland, 2010). Curiosity is the desire to gain new knowledge or experiences. This desire stimulates exploration (Litman and Spielberger, 2003).

One may argue further that during scenario exploration phases, analytical thinking skills to handle inhibitors are required too, especially with the use of tools such as SWOT and internal analysis mentioned by Chermack (2011), and therefore analytical and intuitive reasoning have to complement each other (Evans, 2014).

In sum, the review of pertinent literature reveals the theoretical value of scenario-planning in strategic decision-making. Although there are several premised strategic and behavioral benefits thereof, contextual and process-related variables determine the usefulness of scenarioplanning. A key prerequisite of useful scenarios is proper thinking skills to handle inhibitors and gain the benefits of scenario-planning. 
Table 1: Demographics of informants

\begin{tabular}{|c|c|c|c|c|c|}
\hline Case & Gender & Age & Occupational Level & Organization & Industry \\
\hline 1 & M & 64 & Managing Director & Logistics company & Services \\
\hline 2 & M & 65 & Group Head of Function & Mining company with global presence & Mining \\
\hline 3 & M & 52 & CEO & Manufacturing division of large JSE listed group & Manufacturing \\
\hline 4 & $\mathrm{M}$ & 36 & Deputy Director Operations & Insurance company. JSE listed & Services \\
\hline 5 & $\mathrm{~F}$ & 37 & Head of Function & $\begin{array}{l}\text { Financial services group operating across Africa and other } \\
\text { emerging markets. JSE listed }\end{array}$ & Services \\
\hline 6 & M & 52 & CEO/Managing Director & Industrial division of large JSE listed group & Manufacturing \\
\hline 7 & M & 32 & Head of Function (Growth) & Division of a large JSE listed financial services conglomerate & Services \\
\hline 8 & M & 59 & Executive Chairman & Investment company. JSE listed & Mining \& Manufacturing \\
\hline 9 & M & 47 & Head of Function & $\begin{array}{l}\text { Financial services group operating across Africa and other } \\
\text { emerging markets. JSE listed }\end{array}$ & Services \\
\hline 10 & M & 43 & Head of Function & Top four bank in South Africa. JSE listed & Services \\
\hline 11 & M & 57 & CEO/Managing Director & Manufacturing company part of large JSE listed group & Manufacturing \\
\hline 12 & M & 57 & Manager Commercial Area & South African based global oil company & Energy \\
\hline 13 & $\mathrm{M}$ & 43 & CEO/Managing Director & $\begin{array}{l}\text { South African subsidiary of a UK based group inter alia } \\
\text { manufacturing }\end{array}$ & Manufacturing \\
\hline 14 & $\mathrm{~F}$ & 38 & Senior Manager (Strategy) & $\begin{array}{l}\text { South African based international integrated chemicals and } \\
\text { energy company operating globally }\end{array}$ & Energy \\
\hline 15 & $\mathrm{~F}$ & 42 & CEO/Managing Director & Large business services company in South Africa & Services \\
\hline
\end{tabular}

* JSE = Johannesburg Securities Exchange 


\section{METHODOLOGY}

The study explores the requirements, benefits and inhibitors of scenario-planning by strategic decision-makers operating in the fast-paced complex context of South Africa, the conditions that enable or inhibit the use of scenario-planning as well as the perceived benefits thereof.

An inductive qualitative design was employed. This study focused on executives in South Africa with strategic decision-making responsibilities, and who are likely to practice strategic foresight in large companies and industries such as mining, services, manufacturing and energy. A selection of fifteen executives was obtained through non-probability purposive sampling (see Table 1). Accordingly only executives responsible for strategic decisions for the overall organization (e.g. chief executive officers, managing directors, executive chairmen) or departments of larger organizations (e.g. group head, deputy director, senior manager strategy) were included to represent the 'typical case' of strategic decisions makers in this context (Saunders and Lewis 2012).

Face-to-face semi-structured in-depth interviews were conducted, and data saturation occurred after the twelfth interview. This means that very few new themes or codes emerged after the twelfth interview suggesting diminished value to conduct further interviews (Bowen, 2008; Guest, Bunch and Johnson, 2006).

The average duration of each interview was 50 minutes with a total duration of 744 minutes. With the consent of the participants, the interviews were recorded and transcribed independently. The data was analyzed through thematic analysis (Braun and Clarke, 2006). This involved the generation of a list of codes inductively by observing similarities or patterns in the data through human review as a first phase of analysis. In a second phase of analysis responses were re-examined inductively through ATLAS.ti software (Friese, 2011) to provide certainty that all responses were coded. Supplementary codes were created and responses were re-examined and numbered in relation to the novel codes.

More than one numerical value (corresponding to the codes) was assigned to responses that fit conceptually into more than one code. The coded responses were then examined to provide certainty that the responses that were previously coded were conceptually relevant, and to exclude irrelevant responses, before response frequencies were determined. Categories were determined until clear themes emerged that were compared to themes in literature (Bowen, 2008).

In line with the principles of qualitative research, the research offers rich data on the benefits and inhibitors of scenarios in strategic decision-making in the South African context. Credibility was ensured through suitable semi-structured interview processes, the rigor that the thematic analysis process offers, and triangulation of findings with the literature.

\section{EMPIRICAL FINDINGS}

\subsection{Perceived requirements of effective scenarios}

Table 2 in the Appendix provides an overview of the perceived requirements for scenarioplanning processes to be effective. Effective use of scenario-planning was not industry specific in this study, with mining, manufacturing, services and energy companies making use thereof, although not in every case. 
Table 2: Data on requirements of scenario planning in strategic decision-making

\begin{tabular}{|c|c|c|}
\hline Case & Requirements (key themes) & Sample quotations \\
\hline 8 & Time & $\begin{array}{l}\text { Everyone is more relaxed and everyone has a chance to say something, it is not just two hours. It is a whole afternoon or a } \\
\text { whole morning with a lunch and a few drinks and tomorrow again we unpack. }\end{array}$ \\
\hline 9 & & The biggest one [requirement to implement] is time \\
\hline 10 & & Scenarios... Nee [responding no to question on disadvantages\}. I just think it is time. \\
\hline 14 & & $\begin{array}{l}\text { We don't necessarily do scenario planning for everything, it is where we do see that there are changes or different was that } \\
\text { things could go... because it can be very time consuming. }\end{array}$ \\
\hline 14 & & $\begin{array}{l}\text { It takes a lot of time to plan for things that may or may not have happened, and I think we have to be realistic in the number } \\
\text { of scenarios we run and not get into a situation... }\end{array}$ \\
\hline 5 & Competence and relevance & $\begin{array}{l}\text { We don't play that out as well as we could and that again is linked to skills and competence. You want the kind of people who } \\
\text { can think about that. }\end{array}$ \\
\hline 5 & & $\begin{array}{l}\text { It is easy to do, we haven't been doing it often enough because we are so driven just by the piece of work that we are doing, } \\
\text { this is what we get measured on so this is what we spend most of our time doing. }\end{array}$ \\
\hline 8 & & $\begin{array}{l}\text { We could analyze ourselves into paralysis. If you know too much and you analyze too much you end up doing very little. So } \\
\text { there is that disadvantage and that is why the industry needs people like me who aren't too scared of things they don't know } \\
\text { anything about. }\end{array}$ \\
\hline 9 & & $\begin{array}{l}\text { The effectiveness is basically to what extent are you able to link your scenario analysis to your business as usual and your } \\
\text { business unusual - in the sense of what is going to change. And to what extent does it give rise to management action today } \\
\text { and to a textbook of future management actions... So the effectiveness of scenario analysis is 'how do I link?'... 'What would } \\
\text { I do today and that may include preparing for other scenarios and what would I do given a set of scenarios?' If your scenario } \\
\text { analysis does not give rise to those sets of actions then you are almost wasting time. }\end{array}$ \\
\hline 12 & & $\begin{array}{l}\text { To me the most impactful tools are the tools that just allow the people with the right experience, and it is really around having } \\
\text { the people with the right experience being able to analyze, present options, present the implications of different options. }\end{array}$ \\
\hline 8 & Dedicated space & $\begin{array}{l}\text { My best 'strat' room is the [room name]... When you go in there you will see what I mean. It is very easy to speak about } \\
\text { anything and you can grab your coffee right there. It is very interactive. The tools come up. The things come up on the board } \\
\text { and it has a } 360 \text { vision. You are inside the [company] building and they bring in the guys from the offices as and when we } \\
\text { need them for whatever reason so you have total access to all resources within the [room name]. It is amazing. }\end{array}$ \\
\hline 5 & Consultative culture & $\begin{array}{l}\text { It's people who provide insight that you wouldn't otherwise have encountered or you wouldn't have known. So they provide } \\
\text { the kind of value that you actually find useful to be able to make the right decision or an insightful decision }\end{array}$ \\
\hline
\end{tabular}




\section{Openness and curiosity}

It is liberating if you empower other people to also give their input... If you open it up and you say, listen guys this is what I think is going to happen and this is what I think we should do, what do you think? You stimulate people to such an extent that my management team is starting to anticipate things and they will come to me and say, don't you think we should look at this or this and this.

So you are open and amenable to various inputs to your board and various inputs to your board's strategy based on industry skills availability. So it is not one man who comes up with all the strategies. You listen to a lot of people and get more input. It is important to know sometimes which inputs you require. It is even better to know where to find that input that you require."

You have to be calm and you have to be open minded. If you do that then you can use all of your models and all of those things but you can't make a good decision if you are not calm and you can't make a good decision if you have already decided before you want to make it. 
The findings suggest that adequate time, people and resources need to be allocated to planning:

Sometimes it is not enough in a boardroom with two hours allocated. So we take out a day and we sit in jeans and tops and we say, fine guys, where are we and where do we want to be and where is everybody else? (8)

We don't play that out as well as we could and that again is linked to skills and competence. You want the kind of people who can think about that. (5)

The value of a dedicated space for strategic decisions also emerged:

My best strat room is the [room name]... When you go in there you will see what I mean. It is very easy to speak about anything and you can grab your coffee right there. It is very interactive. The tools come up. The things come up on the board and it has a 360 vision. You are inside the [company] building and they bring in the guys from the offices as and when we need them for whatever reason so you have total access to all resources within the [room name]. It is amazing. (8)

A more pertinent finding seems to be that the culture of the organization should support a consultative approach and empower people and decision-making:

It's people who provide insight that you wouldn't otherwise have encountered or you wouldn't have known. So they provide the kind of value that you actually find useful to be able to make the right decision or an insightful decision. (5)

Another respondent put it this way:

It is liberating if you empower other people to also give their input... If you open it up and you say, listen guys this is what I think is going to happen and this is what I think we should do, what do you think? You stimulate people to such an extent that my management team is starting to anticipate things and they will come to me and say, don't you think we should look at this or this and this. (10)

The leadership group needs to embrace openness, curiosity and an anticipatory attitude to enable the use of scenario-planning in strategic decisions. For instance:

So you are open and amenable to various inputs to your board and various inputs to your board's strategy based on industry skills availability. So it is not one man who comes up with all the strategies. You listen to a lot of people and get more input. It is important to know sometimes which inputs you require. It is even better to know where to find that input that you require. (8)

You have to be calm and you have to be open minded. If you do that then you can use all of your models and all of those things but you can't make a good decision if you are not calm and you can't make a good decision if you have already decided before you want to make it. (10) 
Finally, the scenarios developed should be relevant and actionable:

So the effectiveness of scenario analysis is how do I link... what would I do today and that may include preparing for other scenarios and what would I do given a set of scenarios. If your scenario analysis does not give rise to those sets of actions then you are almost wasting time. (9)

\subsection{Perceived benefits of scenario-planning}

Table 3 in the Appendix offers the data defining several benefits of scenario-planning in strategic decision-making.

The results confirmed two types of benefits relating either to strategic capability or to aspects of organizational behavior. The executives cited several strategy-related benefits of scenarioplanning as illustrated below.

a) increased business agility:

You are going to be having a business that is more prepared for changes, more flexible in its thinking, we are going to be more prepared and able to change faster when these things do change... It creates new opportunities if you have scenarios, you may identify new opportunities for your business - not just risks. (14)

b) identification and mitigation of potential risks:

Are you able to say, well I acknowledge your risk but I am going to act anyway and I am going to mitigate against the risk? I think the thing about empowering people to do exactly that is essential. (4)

c) development of business case robustness:

The scenarios ... affect your planning around your own environmental responsibilities as a manufacturing group. (8)

So scenario-planning is a very important element when it comes to the end of the work that we do... And the result of that is either we have to go and do more work or there is nothing here to be worried about or we have identified something that is really significant that we need to raise awareness of in the business. (5)

The behavioral benefits that emerged were:

a) shifts in leadership thinking:

So those... scenarios then play out in that manner then that they affect your thinking... You don't have to change what you are doing but you can think differently about how you do it going forward. (8)

b) development of a future orientation and anticipatory mindset: 
Table 3: Data on benefits of scenario planning in strategic decision-making

\begin{tabular}{|c|c|c|}
\hline Case & Benefits (key themes) & Sample quotations \\
\hline & Strategy-related benefits: & \\
\hline 1 & Increases business agility & We are able to make decisions with speed and flexibility, we are able to make decisions hugely quickly. \\
\hline 3 & & $\begin{array}{l}\text { So it is not so much about, for us in any case, not so much about what the vision is and where you want to go, etc. We know } \\
\text { what drives us; we need to provide certain financial results. The question is, 'how is the best way of going about it?'; besides } \\
\text { from keeping the money in the bank to create that return. And I think that to a large extent determines our strategy-what we } \\
\text { need to do. It is not driven by a vision or there is a big goal. }\end{array}$ \\
\hline 13 & & $\begin{array}{l}\text { [as part of strategy] looking at scenarios like how exposed we are to commodity prices. I think what is normally done first is } \\
\text { to decide on what your vision is, but we decided to do it the other way and understand the market to develop the vision and } \\
\text { mission around that }\end{array}$ \\
\hline 14 & & $\begin{array}{l}\text { You are going to be having a business that is more prepared for changes, more flexible in its thinking; we are going to be } \\
\text { more prepared and able to change faster when these things do change... It creates new opportunities if you have scenarios, } \\
\text { you may identify new opportunities for your business - not just risks. }\end{array}$ \\
\hline 4 & Mitigates risks & $\begin{array}{l}\text { Are you able to say, well I acknowledge your risk but I am going to act anyway and I am going to mitigate against the risk? } \\
\text { I think the thing about empowering people to do exactly that is essential. }\end{array}$ \\
\hline 4 & & $\begin{array}{l}\text { So you want to try and make sure that there is a high risk, you are aware of those risks, and you make sure that you mitigate } \\
\text { around it that there is a low probability of that risk happening. }\end{array}$ \\
\hline 1 & $\begin{array}{l}\text { Creates business case } \\
\text { robustness }\end{array}$ & $\begin{array}{l}\text { I often find missing in academic understanding of strategy is that it presumes to a large extent that you can control your } \\
\text { destiny... To a large extent you don't! Things happen and unforeseen things happen to you and it is a matter of how you deal } \\
\text { with those, what your capability is... how do you handle things that happen and what is your ability to spot opportunities, and } \\
\text { most importantly, probably opportunities that others don't see or are too scared to grasp, and how do you marshal your } \\
\text { available resources. }\end{array}$ \\
\hline 8 & & The scenarios ... affect your planning around your own environmental responsibilities as a manufacturing group. \\
\hline 9 & & $\begin{array}{l}\text { So I am a big fan of scenario analysis. ... [financial and statistical] models leave out everything that could happen in the } \\
\text { future that you have not experienced yet. Which by definition means it is a shortfall. So the only way you can address that } \\
\text { shortfall is through scenario analysis. So you've got to bring into your sphere of thinking what could happen that you have } \\
\text { not yet experienced. Otherwise all you are doing is looking backward. }\end{array}$ \\
\hline 14 & & $\begin{array}{l}\text { We know what are the big things that are changing, we keep an eye on it and forecast it, the rate of change and we also do } \\
\text { robustness checking, or scenarios... sensitivities ifyou want: if it happens slow or faster and what we will do, that is happening } \\
\text { and it is updated annually or sometimes biannually or quarterly, depending on the rate of change. }\end{array}$ \\
\hline
\end{tabular}


Behavioral benefits:

\section{Shifts leadership thinking}

\section{Enhances participation in} business strategy
And by doing that [defining scenarios at executive level] there are fewer challenges at that level because we are almost gone through the process of being challenged along the way and by the time it gets to them they are more or less on board so they'll be like okay, that makes sense.

So the scenario planning does affect you in that way. You don't have to change what you are doing but you can think differently about how you do it going forward.

Sometimes out of nowhere someone will say something and I will say, I have never thought of that.

They play out in this way, in that you understand the bigger picture, the macro picture. They give you that understanding of the macro picture and it helps you to look at situations in that manner. You don't get frightened easily by micro pictures.

So the only way you can address that shortfall [business models focusing on the past instead of the future] is through scenarioanalysis. So you've got to bring into your sphere of thinking what could happen that you have not yet experienced. Otherwise all you are doing is looking backward.

I find one of the big challenges is really getting people to participate in a planning stage - and I think scenario planning is very good for that as it forces the guys to think about it.

You are going to be having a business that is more flexible in its thinking.

I find one of the big challenges is really getting people to participate in a planning stage - and I think scenario-planning is very good for that as it forces the guys to think about it. 
So the only way you can address that shortfall [business models focusing on the past instead of the future] is through scenario-analysis. So you've got to bring into your sphere of thinking what could happen that you have not yet experienced. Otherwise all you are doing is looking backward. (9)

c) opportunity for participation in business strategy:

I find one of the big challenges is really getting people to participate in a planning stage - and I think scenario-planning is very good for that as it forces the guys to think about it. (13)

The participants did not explicitly mention improved decision-making, organizational learning, improvement in communication or human and organizational performance as cited in literature.

\subsection{Inhibitors of scenario-planning}

The executives mentioned four inhibitors of scenario-planning. The results appear in Table 4 in the Appendix and the findings are discussed next:

Current levels of uncertainty in the market

Although some perceive scenario-planning as an adequate response to uncertainty (Chermack, 2004), it is interesting to note that in practice uncertainty hampers the input into the scenarioplanning process, and may ironically lead to the lack of utilization thereof. One respondent noted:

That was the harsh reality. And the political framework we were operating in. So while there was scenario-planning clearly going on, and very competent scenario-planning ... it gave them options but within the realities of the framework of policy or the political situation within the context of the institution or shareholder demands. So only within that could they put their strategies into place... There were bigger ultimate forces at play. (2)

Global and local economic pressures heighten uncertainty and impacts strategic decisions too:

We were probably lacking in that when we developed the corporate strategy, there was a view and it was tested under various assumptions and it was giving the rate at which we would grow and what businesses we would participate in, was sort of accepted. Then I think we were caught on the back foot when the external environment changed as much as it did from last year. (14)

Having multiple scenarios may even raise levels of uncertainty. Wack (1985) recognizes that the multiple alternatives that scenarios present could be threatening to senior decision-makers who prefer to make choices using judgement based on certainty and facts. One respondent said:

And I think the more scenarios you put in place, the more management feels that you don't know what is going to happen ... We also have to limit the number of ways things can change; to me two or three is the most you should have. You have to manage that uncertainty and doubt, otherwise you are opening up everything. You have to have a realistic view that it is going to be this or this. (14) 


\section{Table 4: Data on inhibitors of scenario planning in strategic decision-making}

\begin{tabular}{|c|c|c|}
\hline Case & Inhibitors (key themes & Sample quotations \\
\hline 2 & Uncertainty in the market & $\begin{array}{l}\text { That was the harsh reality. And the political framework we were operating in. So while there was scenario-planning clearly going } \\
\text { on, and very competent scenario-planning ... it gave them options but within the realities of the framework of policy or the political } \\
\text { situation within the context of the institution or shareholder demands. So only within that could they put their strategies into place. }\end{array}$ \\
\hline 4 & & $\begin{array}{l}\text { So if you are making a two year assumption anything could happen in two years. You could have a major financial crisis that blows } \\
\text { out all of your assumptions. So those types of things happen pretty much all the time so you have to be able to assess what you are } \\
\text { doing with assumptions. }\end{array}$ \\
\hline 6 & & I don't know what is going to happen tomorrow -- what do you want me to tell you what is happening in 5 years' time? \\
\hline 7 & & $\begin{array}{l}\text { So we are not a big long term scenario planning type organization. We 're a lot more agile and a lot more responsive and as a result } \\
\text { the value of long term planning I don't think is relevant to us as an organization... . But that is as far as our scenario planning goes, } \\
\text { we really, we prefer to be agile around our approach. We prefer to have data dictate to us how we manage our pipeline. }\end{array}$ \\
\hline 11 & & $\begin{array}{l}\text { I would be fascinated to know how many people are using five year planning in a world where product life cycle is so short. There } \\
\text { are so many disrupters that come into the market that can mess those plans up radically. }\end{array}$ \\
\hline 14 & & $\begin{array}{l}\text { We were probably lacking in that when we developed the corporate strategy: there was a view and it was tested under various } \\
\text { assumptions and it was giving the rate at which we would grow and what businesses we would participate in, was sort of accepted. } \\
\text { Then I think we were caught on the back foot when the external environment changed as much as it did from last year. }\end{array}$ \\
\hline 14 & & $\begin{array}{l}\text { And I think the more scenarios you put in place, the more management feels that you don't know what is going to happen ... We } \\
\text { also have to limit the number of ways things can change; to me two or three is the most you should have. You have to manage that } \\
\text { uncertainty and doubt, otherwise you are opening up everything. You have to have a realistic view that it is going to be this or } \\
\text { this. }\end{array}$ \\
\hline 2 & Lack of agility of scenarios & $\begin{array}{l}\text { So even though I reported into the board we did not get a chance to go and change the board scenarios... You didn't pursue it } \\
\text { regardless just because it was set as a scenario at a board level. }\end{array}$ \\
\hline 4 & & We prefer to be agile around our approach. We prefer to have data dictate to us how we manage our pipeline. \\
\hline 4 & & $\begin{array}{l}\text { A lot of people look at all of the high road scenarios and say well this is the most elegant and profitable business case. The reality } \\
\text { is one... if one variable doesn't play out in favor your entire structure collapses. So you have to consider the high road / low road } \\
\text { scenario. }\end{array}$ \\
\hline 6 & & $\begin{array}{l}\text { Look I can never say, one can never say that you think scenario planning is rubbish. Because there is a place for it. There is certainly } \\
\text { a place for it: you have to think about tomorrow and what happens if this happens and that happens. I have no doubt that there are } \\
\text { companies in this country that do proper scenario planning. And they think this is the right thing to do. For me and it's just my own } \\
\text { personal view, flexibility is the name of the game. So never ever ignore what these scenarios say but I don't believe you have to go }\end{array}$ \\
\hline
\end{tabular}


into 50 different scenarios, some say 50 shades of grey, and work out what all these things are. Because the world is just an ever changing place.

Disconnect between scenarios and outcomes

2

You couldn't scenario plan that. That's why I'm saying... there are times when it works and times when it doesn't quite work, but you can't sit back and not plan because then you are planning to fail.

These are different scenarios, where are we going to go - no, it changes too quickly and it is so much effort spent on that.

The ambiguity we are trying to embrace is wide... So there is a tipping point beyond which we can't go and I have got to be very mindful as to where those barriers are, to say 'guys you are too far over there, come back'.

Even a scenario that identifies that we are going to do this and issues came into play and then you never pursued it.

The board went ahead and pursued it at enormous expenses and it's still playing out as we sit here. Every year they just wrote down another 4 billion or 5 billion.

So you play out those possibilities to see how you should react to that. It doesn't leave you with a lot of options though, but at least you have thought about it.

I mean if I had to go and map out, do an official structured scenario plan, the branches and options and what have you are going to have will be very limited, because there are only so many things that you can do. There are only so many things that can happen.

So that is what I mean by limited; there is so much that you can do, there's not a lot of options that you can plot out in terms of what can happen and how you are going to react to it.

Yes I think the difference or the key success is not the agility in thinking it is the agility in doing. So it is no use scenario planning if you are not going to do anything about it. So you know you have got to attack your scenarios. You only scenario plan for your advantage. So if you are not going to do anything to create advantage then why scenario plan?

From a scenario planning perspective, I don't know the organization does that [implementation] much in terms of actually understanding depending on the route they go, this is the result we are 'gonna' get to. And you see that a lot in failed projects.

It is difficult to really say here is real value out of that exercise. I guess it is because you don't see that until the next generation or the next decade. You can't see it in the financial results at the end of the year. ... I guess a lot of the shifts that are being done, the ideas that have popped out of somebody's early morning not being able to sleep and an idea comes out. That probably has more impact and more visible impact than going through a full scenario-planning exercise.

We were probably lacking in that when we developed the corporate strategy, there was a view and it was tested under various assumptions and it was giving the rate at which we would grow and what businesses we would participate in, was sort of accepted. Then I think we were caught on the back foot when the external environment changed as much as it did from last year, what is happening currently is the corporate strategy is being reviewed and the robustness of this under various scenarios is being tested.

And everybody has got to come back to me with a comment. Sometimes there is nothing, sometimes there's something; but you weave all of that into the scenario; into the strategies at the end of the day-without calling it scenario planning or strategic discussions. 
I don't have enough resources; I need to invest in that. If we had teams of analytical people we might happily do more scenarioplanning, but we don't.

Typically the executives would lack the detail to go beyond the unpacking. They would talk - conceptually around the unpacking and conceptually around the impact and conceptually around their resulting management action.

So the methodology: that it is the missing link. So methodology, if you read scenario-planning books there is a lot around the theory and the concept, very little about the how.

It takes a lot of time to plan for things that may or may not have happened, and I think we have to be realistic in the number of scenarios we run.. 
These findings suggest that scenarios may not fully prepare leaders for the unexpected, and contrary to theory, even raise feelings of uncertainty for some.

Scenarios are not agile or responsive enough

Several leaders were critical about scenarios and strategic planning. The next three quotes illustrate this:

There is no such thing as five years. I don't know what is going to happen tomorrow, what do you want me to tell you what is happening in five years' time. (6)

We prefer to be agile around our approach. We prefer to have data dictate to us how we manage our pipeline. (4)

I would be fascinated to know how many people are using five year planning in a world where product life cycle is so short. There are so many disrupters that come into the market that can mess those plans up radically. (11)

In theory Chermack et al. (2015) have positioned scenario-planning as an enabler of organizational agility. It would seem that in practice cumbersome scenario processes could inhibit agility in strategic decision-making. Schoemaker's (1995) call for continual scanning of the environment may present solutions to this challenge. Decision-makers may require continual alerts of changing trends, rather than static long-term plans.

Disconnect between scenario-planning and outcomes

Scenarios are often developed years before the impact of the environmental forces may be seen on the company. According to the findings, a sense of disconnection may occur between the time of planning and the ultimate outcome of events. In the complex context several unanticipated extraneous events may also determine actual outcomes, which reinforces doubts regarding the effectiveness of scenario-planning:

It is difficult to really say here is real value out of that exercise. I guess it is because you don't see that until the next generation or the next decade. You can't see it in the financial results at the end of the year. ... I guess a lot of the shifts that are being done, the ideas that have popped out of somebody's early morning not being able to sleep and an idea comes out. That probably has more impact and more visible impact than going through a full scenario-planning exercise. (12)

It appears that in order to optimize the benefits of scenarios, organizational strategists need tools and processes that facilitate an understanding of nonlinear relations between company actions and outcomes.

Questionable practicality of process

Several of the executives interviewed mentioned the costs of the process, echoing Wilburn and Wilburn's (2011) view that scenario-planning is time- and resource-intensive. The following comments illustrate:

I don't have enough resources; I need to invest in that. If we had teams of analytical people we might happily do more scenario-planning but we don't. (15) 
It takes a lot of time to plan for things that may or may not have happened, and I think we have to be realistic in the number of scenarios we run... (14)

If scenario analysis does not give rise to those sets of actions then you are almost wasting time. (9)

This implies that unless scenarios enable the proactive prevention of the potential negative impact of unexpected events in experience, few will adopt the extended process required for full scenario-planning sessions.

One person also commented on lack of capacity of executives to anticipate probability of events:

Typically the executives would lack the detail to go beyond the unpacking. They would talk - conceptually around the unpacking and conceptually around the impact and conceptually around their resulting management action. (9)

There also seems to be insufficiencies in the facilitation of scenario sessions:

So the methodology. That it is the missing link. So methodology, if you read scenarioplanning books there is a lot around the theory and the concept, very little about the how.

\section{DISCUSSION OF FINDINGS}

The findings of this study suggest poor utilization of scenarios in strategic decision-making in the South African context, linked to practical inhibitors, process inadequacies and environmental constraints, despite the potential benefits thereof.

Based on the findings of this study, a research implication is that trend focused probability computation in scenario-planning may have become superfluous for most executives making decisions in a complex world. It would seem from the findings that strategic decision-makers in this context favor a plausibility over a probability approach to scenarios. As per Ramírez and Selin (2014) a plausibility approach suggests that decision-makers do not seek to predict a given future over others, but instead create multiple potential futures through scenarios. In response to this we propose that strategic decision-makers require growth in scenario thinking competencies that create a changed mindset to develop strategic agility for organizations through practices of inter alia intuitive logic.

Furthermore, as demonstrated by Ramírez, Roodhart and Manders (2011) the integration of strategic decision-making, scenarios thinking and technological innovation requires the creation of domains or structures with distinct prerequisites such as effective engagement of senior management, careful selection of projects connected to business, and an actionable vision, in order to grow business value. Domains need to be continually tested and should interlink not only technologies, strategies and scenarios with each other, but also with the external system.

Given the multiple requirements and inhibitors of scenario-planning revealed in reported findings, in order to gain benefits there may be a need for simplified methodologies and practical tools to allow decision-makers to be better prepared for uncertain futures. There is also a need for technological support for agile decision-making. 
Given the time constraints of scenario processes, we propose that investments should be conducted into time-saving software solutions for the computational, trend- and cross impact analyses to free executives up to practice scenario-thinking and agile decision-making. For example, Voudouris et al. (2014) demonstrate how the innovative computational softwarebased ACEGES model enables continuous scenarios specifically for the natural gas industry. Making use of artificial intelligent agents the model yields trend scenarios. Future research may explore the use of machine learning and artificial intelligence as enablers of scenario thinking.

Beyond trends-based software solutions, executives need to develop intuitive logic and strategic agility. The findings suggest that agility is critical to the executives and, for many, is based on taking a series of smaller decisions and continually scanning the environment, rather than large scale decisions based on a number of stories about futures. Frequent decisions may prevent the inertia that follows from multiplying options.

Therefore, practitioners could explore how 'un-smart' technology that presents continual and relevant information to decision-makers could be of benefit. Such technologies may help support an agile future-oriented mindset. Practitioners may also focus on the development of simple exercises that shape intuitive logic. As it is recommended that the methodologies support the maintenance of the community benefits of scenarios development, the exercises may be integrated into board and managerial meetings and communication, rather than onceoff strategy sessions.

\section{RESEARCH IMPLICATIONS}

Given variability in the use of scenario-planning processes, essential process requirements and the implications of benefits and inhibitors, the use of scenarios thinking in strategic decisionmaking should be improved. Figure 1 provides an overview of the key findings of this study.

Figure 1: Inhibitors, enablers and benefits of scenario-planning in strategic decision-making

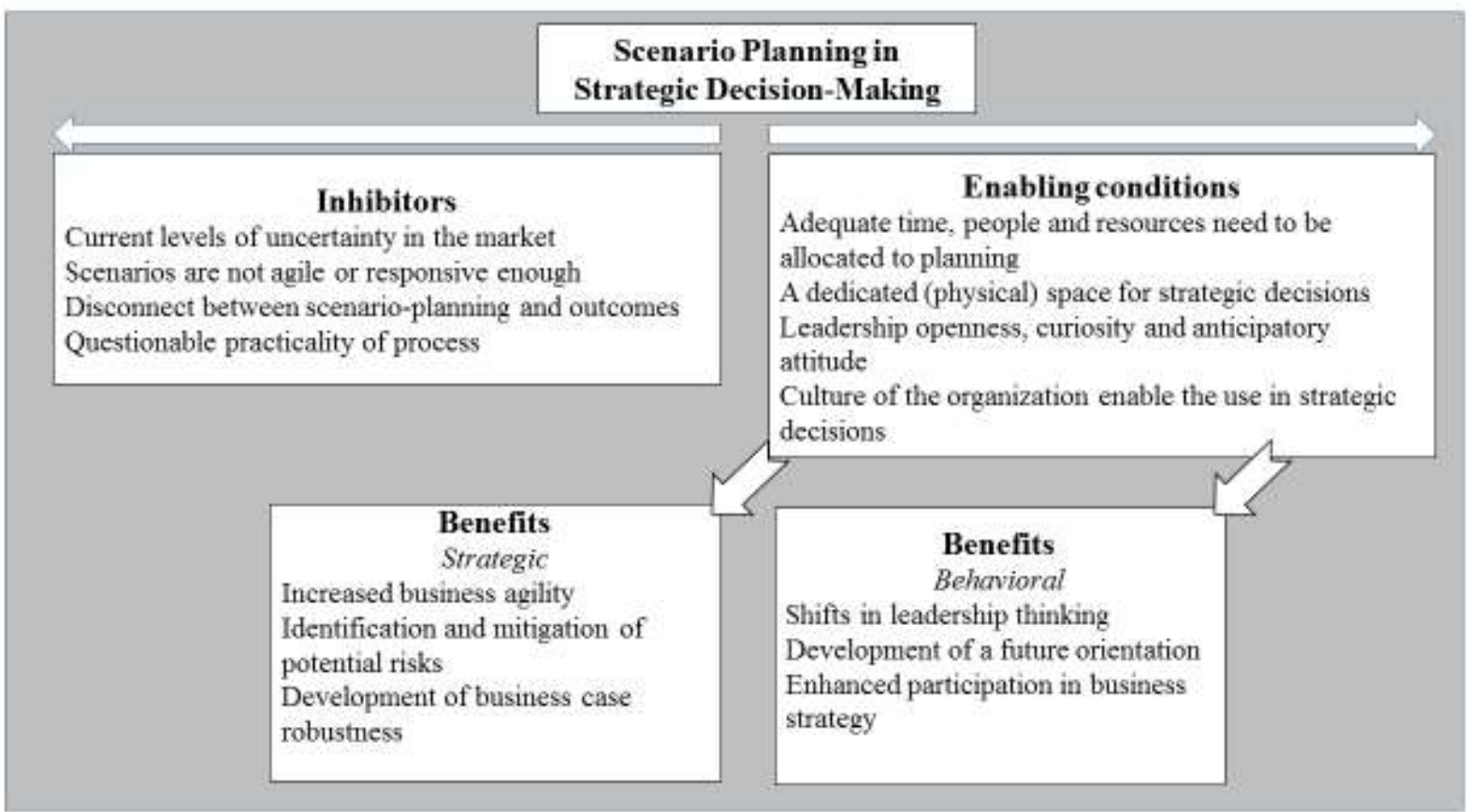


Figure 1 indicates that there are multiple requirements, benefits and inhibitors involved in scenario-planning, all of which become relevant to take into consideration in strategic decisionmaking. The requirements for the process to work includes not only a culture in which leaders are open to uncertainty, and enable strategic choice, but also practical requirements of the right resources, spaces and planned time to allow for it. The emerging market managers recognized the value of scenario-planning. It is of strategic value to organizations, where risks are identified and mitigated, the business becomes agile and the business case robust through scenario-planning. Beyond strategic decision-making benefits, it brings opportunity to develop the leaders' thinking, future orientation, as well as alertness and offers the opportunity to participate in strategic decision-making. Despite these benefits, reluctance to use scenarioplanning stems from a mismatch between the turbulence of the business world and a perceived rigidity that develops once scenarios are formulated, along with mismatched outcomes and impractical processes.

A balanced view of scenario-planning indicates that the benefits of the process have been marred by the application thereof in decision processes. This was already the case in the early 1980s where Klein and Linneman's (1981) multi-case analysis showed that companies varied in the degree to which managers understood and were involved in scenarios, and the degree to which scenarios were integrated or ad hoc in either the corporate or divisional planning processes.

Although in practice strategic decision-makers understand the importance of remaining mindful of risks, they may not have the time available to generate scenarios, nor see the links between plans and outcomes. Cultivating an integrated scenario thinking competence remains an essential prerequisite of strategic decision-making, and this may be augmented through tools and processes supportive of both trends analysis and iterative decision-making.

With that in mind the framework of integrative thinking in strategic decision-making displayed in Figure 2 highlights the need to not only develop computational processes to define interdependencies, which may be performed by artificial intelligence, but also to develop agile mindsets that support the formulation of adequate responses to evolving futures.

Kaplan and Beinhocker (2003) state that although companies have invested financial resources and time in strategic planning, few executives see the benefit of such investment. According to them strategic planning, which may include scenarios, is not about creation of strategy, but about preparing people's minds to make good strategic decisions.

\section{MANAGERIAL IMPLICATIONS}

The findings compiled in Tables 2 to 4 provide a foundation of several research implications of meeting the requirements, gaining the benefits and handling the inhibitors of scenarioplanning, such as an integrated framework of thinking skills in strategic decision-making rather than relying on scenario-planning as a tool, as shown in Figure 2. 
Figure 2: A framework of integrative thinking in strategic decision-making

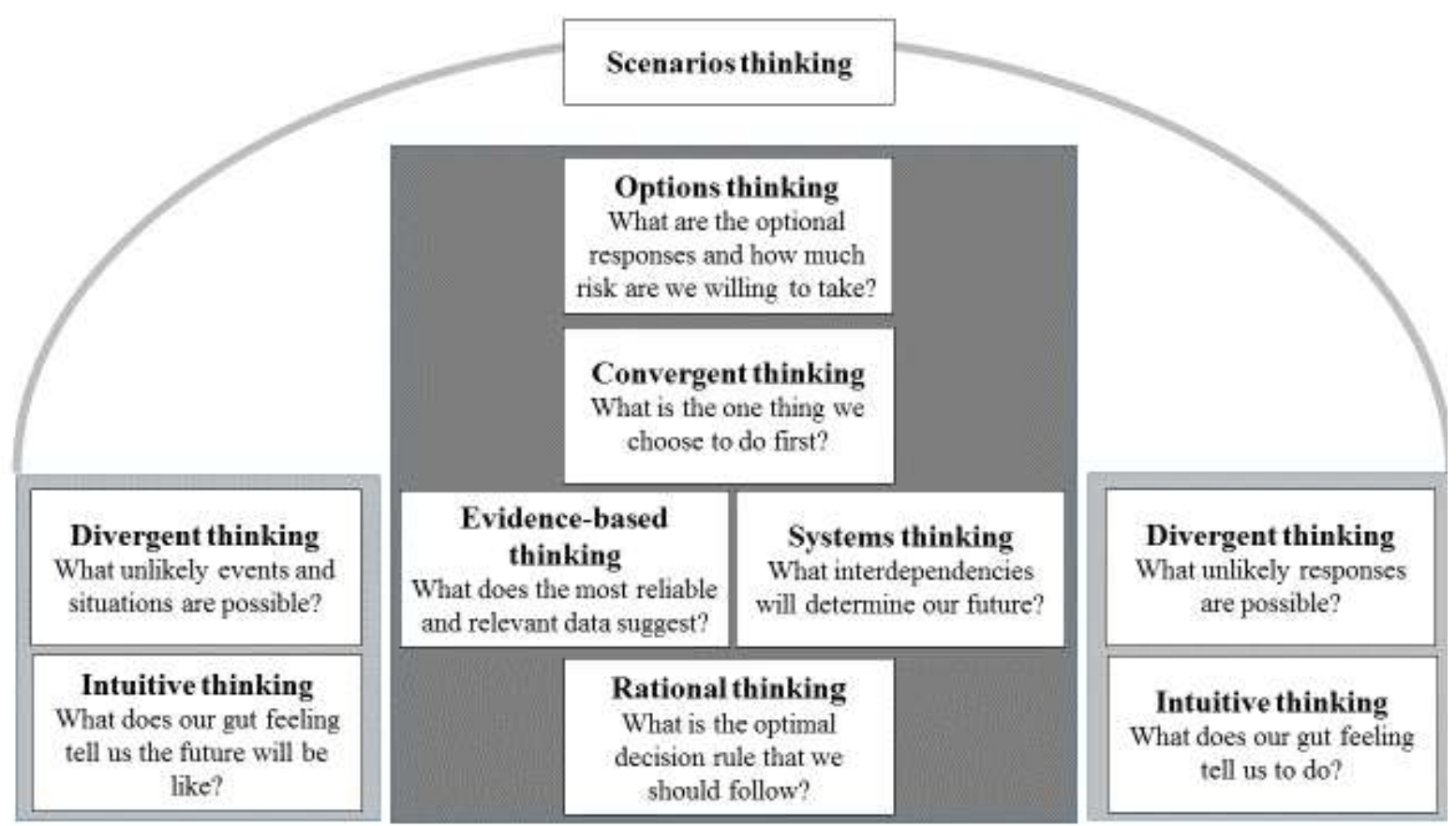

Source: Authors'own

Decision-makers need draw on both intuitive and rational processes, as well as divergent and convergent thoughts in scenario-planning. There is no prescribed sequence implied, but the logic would suggest that decision-makers need to uncover many new ideas about likely events and potential responses through divergent thinking linked to intuition.

Divergent thinking has been defined as the thinking style that yields novel, unique ideas and explores many possible solutions, as opposed to convergent thinking aimed at generating a single answer to problems (Guilford, 1967).

Decision-makers need to balance intuitive thinking with reflective thinking (Evans, 2014). Drawing on information from the past, decision-makers should determine the optimal decision rule that will maximize the possibility of the best outcome (Schoemaker and Russo, 1993; Schul and Mayo, 2003). Rational thinking is supported by the evidence-based thinking as defined before (Baba and HakemZadeh, 2012).

Systems thinking then helps overcome the limitations associated with complex systems when the decision-makers have to consider the organization's relationship to its environment as well as the dynamic and complex nonlinear relationships, interdependences and influences between the organization and the world in which it operates (Caldwell, 2012). Systems thinking (taking into account the hierarchy of systems at play) and reflective practice will improve scenario processes (Lang and Allen, in Ramírez, Selsky and Van der Heijden, 2010).

Powell (2014) states that there is a mutuality between systems thinking and scenarios thinking as scenario analysis presupposes assumptions about the behavioral characteristics of the predicted future system. The cluster of rational, systems and evidence-based thinking constitutes the logical thinking required in strategic decisions. 
Intuitive and divergent thinking is also used to determine a range of possible responses to plausible futures. When considering these responses strategic decision-makers require options thinking skills (Driouchi and Bennett, 2012) in order to allow flexibility and risk mitigation.

Real options thinking “embeds a firm's ability to sequence, stage and reverse commitment in the face of uncertainty" (Driouchi and Bennett, 2012, p. 41). Ultimately, to encourage action based on the cumulative insights from the intuitive and rational processes, decision-makers need to rely on convergent thinking (Guilford, 1967) to choose a best first action.

Therefore, scenarios thinking forms part of a web of thinking competencies that enables positive strategic decisions in the face of uncertainty and complexity. Figure 2 offers a series of simple questions that decision-makers may ask while developing strategic decision-making competencies. Hacklin and Wallnöfer (2012) point out that dominant mental frames impede strategic change and inform strategic thinking. It is proposed that by utilizing the different thinking skills and mental frames of the collective, decision-makers can allow agility in thinking about the future.

\section{CONCLUSIONS AND SUGGESTIONS}

Given the increasing complexity of the business environment, this study contributes to a framework of scenario thinking that stresses greater emphasis on developing strategic decisionmaking competence, changed mindsets, and organizational agility. Further, it contributes to identify a set of requirements, benefits and inhibitors of scenario-planning in strategic decisionmaking. From the cases studied it is evident that industry, organizational and leadership related factors enable or inhibit scenario-planning.

We conclude that the findings reported expand the insights into the requirements, benefits and inhibitors of scenario-planning in strategic decision-making.

We recognize a number of limitations in this study that offer a foundation for future research to assess validity, reliability and transferability of the findings reported. The study was conducted only in an emerging market context. It only offers insights into practitioners' perceptions of the benefits, inhibitors and enablers of scenario-planning in strategic decisionmaking. Nevertheless, these research limitations provide opportunities for further research in other emerging markets. A longitudinal study could measure the extent to which scenarios display the perceived benefits.

Further research to determine supportive tools and technologies for enabling scenario-planning across multiple contexts is needed. For example, research may explore the technologies that enable trend awareness, strategic thinking and decision-making and changed mindsets. The proposed framework of integrative thinking in strategic decision-making may be used in practical workshops with executives to broaden their thinking and lay a foundation for more effective scenario-processes.

\section{References}

Baba, V.V. and HakemZadeh, F. (2012), "Toward a theory of evidence based decision-making", Management Decision, Vol. 50 No. 5, pp. 832-67. 
Bootz, J. (2010), "Strategic foresight and organisational learning: A survey and critical analysis", Technological Forecasting \& Social Change, Vol. 77, pp. 1588-94.

Bowen, G.A. (2008), "Naturalistic inquiry and the saturation concept: a research note", Qualitative Research, Vol. 8 No. 1, pp. 137-52.

Burt, G., Wright, G., Bradfield, R., Cairns, G. and Van der Heijden, K. (2006), "The role of scenario planning in exploring the environment in view of the limitations of PEST and its derivatives", International Studies of Management \& Organisation, 36, 3, pp. 50-76.

Cairns, G., Goodwin, P. and Wright, G. (2016), "A decision-analysis-based framework for analysing stakeholder behaviour in scenario-planning", European Journal of Operational Research, Vol. 249 No. 3, pp. 1050-62.

Caldwell, R. (2012), "Systems thinking, organisational change and agency: A practice theory critique of Senge's learning organisation", Journal of Change Management, Vol. 12 No. 2, pp. 145-164.

Chermack, T.J. (2004), "A theoretical model of scenario-planning", Human Resource Development Review, Vol. 3 No. 4, pp. 301-25.

Chermack, T.J. (2011), Scenario-planning in organisations: How to create, use and assess scenarios, Barrett-Koehler, San Francisco, CA.

Chermack, T.J., Bodwell, W. and Glick, M. (2010), “Two strategies for leveraging teams toward organisational effectiveness: scenario planning and organisational ambidexterity", Advances in Developing Human Resources, Vol. 12 No. 1, pp. 137-56.

Chermack, T.J., Coons, L.M., Nimon, K., Bradley, P. and Glick, M.B. (2015), "The effects of scenario-planning on participant perceptions of creative organisational climate", Journal of Leadership \& Organisational Studies, Vol. 22 No. 3, pp. 355-71.

Chermack, T.J. and Lynham, S.A. (2002), "Definitions and outcome variables of scenario planning", Human Resource Development Review, Vol. 1 No.3, pp. 366-83.

Chermack, T.J. and Nimon, K. (2013), "Drivers and outcomes of scenario-planning: a canonical correlation analysis”, European Journal of Training \& Development, Vol. 37 No. 9, pp. 81134.

Chermack, T.J. and Swanson, R.A. (2008), "Scenario-planning: human resource development's strategic learning tool", Advances in Developing Human Resources, Vol. 10 No. 2, pp. 129-46.

De Geus, A.P. (1988), "Planning as learning”, Harvard Business Review, Vol. 66 No. 2, pp. 70-4.

Driouchi, T. and Bennett. D.J. (2012), "Real options in management and organisational strategy: A review of decision-making and performance implications", International Journal of Management Reviews, Vol. 14, pp. 39-62.

Duncan, N.E. and Wack, P. (1994), "Scenarios designed to improve decision making", Planning Review, Vol. 22 No.42, pp. 18-46.

Evans, J.T. (2014), “Two minds rationality”, Thinking \& Reasoning, Vol. 20 No. 2, pp. 129-46

Friese, S. (2011), ATLAS.ti 6.0 User Manual, ATLAS.ti Scientific Software Development, Berlin, Germany. GmbH. Available from http://www.atlasti.com/

Guest, G., Bunce, A. and Johnson, L. (2006), "How many interviews are enough? An experiment with data saturation and variability", Field Methods, Vol. 18 No. 1, pp. 59-82. 
Guilford, J.P. (1967), The nature of human intelligence, McGraw-Hill, New York.

Hacklin, F. and Wallnöfer, M. (2012), "The business model in the practice of strategic decisionmaking: insights from a case study”, Management Decision, Vol. 50 No. 2, pp.166-88.

Hammoud, M.S. and Nash, D.P. (2014), "What corporations do with foresight", European Journal of Futures Research, Vol. 2 No. 42, pp. 1-20.

Harris, G. (2014), "Four blind alleys of scenario analysis", Strategy \& Leadership, Vol. 42 No. 6, pp. 36-41.

Højland, J. and Rohrbeck, R. (2018), "The role of corporate foresight in exploring new markets evidence from 3 case studies in the BOP markets", Technology Analysis \& Strategic Management, Vol. 30 No. 6, pp. 734-46.

Kaplan, S. and Beinhocker, E. (2003), "The real value of strategic planning", MIT Sloan Management Review, Vol. 44 No. 2, pp. 71-6.

Kum, M.E. (2017), "R\&D intensity and corporate foresight -Their relationship and joint impact on firm performance: A longitudinal analysis in large firms", Proceedings of ISPIM Conferences, pp. 1-15.

Klein, H.E. and Linneman, R.E. (1981), "The use of scenarios in corporate planning: Eight case histories”, Long Range Planning, Vol. 7 No. 1, pp. 31-47.

Lang, T. and Allen L. (2010), "Reflecting on scenario practice: The contribution of a soft systems perspective", in Eds. Ramírez, Rafael, John W. Selsky, and Kees Van der Heijden, Business Planning for Turbulent Times: New Methods for Applying Scenarios, Taylor \& Francis.

Lewis, M.W., Andriopoulos, C. and Smith, W.K. (2014), "Paradoxical leadership to enable strategic agility”, California Management Review, Vol. 56 No. 3, pp. 58-77.

Litman, J.A. and Spielberger, C.D. (2003), "Measuring epistemic curiosity and its diversive and specific components", Journal of Personality Assessment, Vol. 80, pp. 75-86.

Matzler, K., Uzelac, B. and Bauer, F. (2014), "Intuition's value for organisational innovativeness and why managers still refrain from using it", Management Decision, Vol. 52 No. 3, pp. 52639.

McWhorter, R. and Lynham, S. (2014), “An initial conceptualization of virtual scenario-planning”, Advances in Developing Human Resources, Vol. 16 No. 3, pp. 335-55.

Powell, J. H. (2014), "System/scenario duality: A supporting equivalence", Journal of The Operational Research Society, Vol. 65 No. 9, pp. 1344-60.

Ramírez, R. and Selin, C. (2014), "Plausability and probability in scenario planning", Foresight, Vol. 16 No. 1, pp. 54-74.

Ramírez, R., Churchhouse, S., Hoffman, J. and Palmero, A. (2017), "Using scenario planning to reshape strategy", MIT Sloan Management Review, Vol 58 No. 5, pp. 31-7.

Ramírez, R., Roodhart, L. and Manders, W. (2011), "How Shell's domains link innovation and strategy", Long Range Planning, Vol. 44 No. 4, pp. 250-70.

Ringland, G. (2010), "The role of scenarios is strategic foresight", Technological Forecasting \& Social Change, Vol. 77, pp. 1493-8.

Rohrbeck, R., Battistella, C. and Huizing, E. (2015), "Corporate foresight: An emerging field with a rich tradition”, Technological Forecasting and Social Change, Vol. 101, pp. 1-9. 
Rohrbeck, R., Kum, M.E. and Jissink, T. (2017), Corporate Foresight: Benchmarking Report 2017, Aarhus, Denmark: Aarhus University, Aarhus School of Business and Social Sciences.

Sargut, G. and McGrath, R.G. (2011), "Learning to live with complexity", Harvard Business Review, Vol. 89 No. 9, pp. 68-76.

Saunders, M. and Lewis, P. (2012), Doing Research in Business and Management: An Essential Guide to Planning your Project. England: Pearson Education Limited.

Schul, Y. and Mayo, R. (2003), "Searching for certainty in an uncertain world: The difficulty of giving up the experiential for the rational mode of thinking", Journal of Behavioural Decision Making, Vol. 16 No. 2, pp. 93-106.

Smith, E. (2008), "The role of intuition in collective learning", Advances in Developing Human Resources, Vol. 10 No. 4, pp. 494-508.

Schoemaker, P.J. (1995), "Scenario-planning: a tool for strategic thinking", Sloan Management Review, Vol. 36 No. 2, pp. 25.

Schoemaker, P.J.H. and Russo, J.E. (1993), "A pyramid of decision approaches", California Management Review, Vol. 36 No. 1, pp. 9-31.

Snowden, D. (2003), "Complex acts of knowing: paradox and descriptive self-awareness", Bulletin of the American Society for Information Science \& Technology, Vol. 29 No. 4, p. 23-8.

Van der Merwe, L. (2008), "Scenario-based strategy in practice: a framework", Advances in Developing Human Resources, Vol. 10 No. 2, pp. 216-39.

Vecchiato, R. (2012), "Environmental uncertainty, foresight and strategic decision-making: an integrated study", Technological Forecasting \& Social Change, Vol. 79, pp. 436-47.

Vecchiato, R. and Roveda, C. (2010), "Strategic foresight in corporate organisations: Handling the effect and response uncertainty of technology and social drivers of change", Technological Forecasting \& Social Change, Vol. 77, pp. 1527-39.

Voudouris, V., Matsumoto, K., Sedgwick, J., Rigby, R., Stasinopoulos, D. and Jefferson, M. (2014), "Exploring the production of natural gas through the lenses of the ACEGES model", Energy Policy, Vol. 64, pp. 124-33.

Wack, P. (1985), "Scenarios: Shooting the rapids", Harvard Business Review, Vol. 63 No. 6, pp. 139-50.

Werner, M. (1990), "Planning for uncertain futures: building commitment through scenario planning", Business Horizons, Vol. 33 No. 3, pp. 55-8.

Wilburn, K. and Wilburn, H. (2011), "Scenarios and strategic decision-making”, Journal of Management Policy \& Practice, Vol. 12 No. 4, pp. 164-78.

Wilson, I. and Ralston, J. (2006), The Scenario-Planning Handbook: Developing Strategies in Uncertain Times, Cengage Learning Inc, Mason, Ohio.

Yoon, J. Kim, Y. Vonortas, N. and Han, S. (2018), "Corporate foresight and innovation: The effects of integrative capabilities and organisational learning", Technology Analysis \& Strategic Management, Vol. 30 No. 6, pp. 633-45. 